UDK: 28:347.62

Primljeno: 5. 10. 2021.

Prethodno priopćenje

Prihvaćeno za štampu: 21. 11. 2021.

\author{
Dr. sc. Muharem Štulanović, redovni profesor \\ Univerzitet u Bihaću \\ Islamski pedagoški fakultet \\ E-mail:ebuseba@hotmail.com
}

\title{
POTREBA ZA FETVOM IZ-E BIH O SVJEDOČENJU ZA RAZVOD BRAKA I POVRAT ŽENE
}

\section{Sažetak}

Općepoznato je da bračno, porodično pravo i razvod imaju svoju pravnošerijatsku regulativu koju su obradili pravnici s pravnog i fikhskog aspekta. Rastava braka postaje izuršena izgovorom i terminima koji znače rąuod nakon završenog postbračnog pričelea1.

-Grupa uleme je na stajalistu da se razvod računa u situaciji kada suprug (pravni adresat) izgovori termine/izraze neopozivog razvoda, pa makar $i$ ne namjeravao rastavu po hadisu:

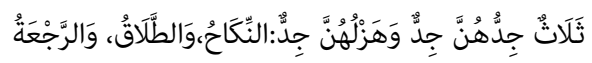

Tri stvari su ozbiljne i u šali: brak, rąvod i vraćanje žene u bračnu zajednicu.2

-Ulema islamskog ummeta slaže se da je osnova razuoda jezičcki izgovor terminal izraza koji znače razuod što se može iskazati i pismeno, kao $i$ znakounim jezikom i išaretom. U tom smislu su kur'ansko-hadiski tekstovi i norme koje govore o razuodu.

${ }^{1}$ Dr. Vehbe ez-Zuhajli, El-Fikhul-islami ve edilletuh, 9/6873.; Ibn Abidin, Hašije, $3 / 226$.

${ }^{2}$ Zabilježili su ga autoriteti hadisa Ebu Davud, br.: 2194., Tirmizi: 1184., Ibn Madže, 2039., Hakim, 2/198. Tirmizi je nakon citiranja hadisa naveo: Hadis je hasen garib. Uprkos tome, praksa na osnovu njega bila je kod uleme, učenih ashaba Allahovog Poslanika, s.a.v.s., i drugih. 
-Razvod je jezički, verbalni postupak od strane supruga koji daje razvod svojom autonomijom volje. To je njegovo diskreciono pravo, a ne ngovor u kojem treba da se podudare dvije volje ili šrenina dozvola.

-U ovom vremenu, kada vlada opía pokvarenost i nemoral, ljude treba obavezivati na registraciju $i$ zapisivanje važnih ali $i$ manje važnih ugovora kako bi se spriječilo uzimanje, prisvajanje ili propadanje prava koja nisu zabilježena $i$ zapisana te tako zaustavile svade i netrpeljivosti zbog imovinskih i drugib nesporazuma.

-U tom smislu su svjedocenje i registracija braka, a isto tako rastave i razvoda, postali potreba u IZ BiH uzpoznatu cinjenicu da je to uobičajena praksa u konvencionalnom pravu kao i u nekim savremenim, muslimanskim zemljama.

\section{Ključne riječi}

Brak, bračna zajednica, razuod, rastava, svjedočenje kod rastave i razuoda, postbračno cekanje/iddet.

\section{Uvod}

Ugovor, kojim se grade bračni odnosi u islamu, ima takvu svetost da ga Uzvišeni tretira kur'anskim izrazom koji bismo u slobodnom prijevodu mogli nazvati ,podebljani, čvrsti ugovor, obaveza“ (misakan galizan). Uzvišeni kaže:

وَأَخَذْنَ مِنَمُمِ مِينَاقَا غَلِيظًا

i kada su one od vas čvrstu obavezu uzele. (Kur'an, 4: 21)

Uzvišeni ga je propisao tako važnim i značajnim zbog zaštite bračnog života utemeljenog na ljubavi i empatiji supružnika kojima će čuvati jedno drugo neporočnim u misiji reprodukcije čovječanstva, produžetku vrste, izgradnji društva i najljepšem načinu izvršavanja povjerene misije izgradnje i civiliziranja čovjeku povjerenog ovog dunjalučkog svijeta.

U slučaju da dođe do narušavanja bračnih odnosa, međusobnog razlaza u poimanju i tretmanu zajedničkih koristi i nepodudaranju njihove prirode $\mathrm{u}$ tako senzibilnim odnosima, izostanak komunikacije, emotivno udaljavanje supružnika, razni oblici nasilja, zbog nemorala jednog od njih ili zbog nekih drugih razloga koji su pretvorili te odnose u životnu netrpeljivost koja ne dozvoljava zajedničko življenje, onda, 
Uzvišeni je, iz milosti prema ljudskoj vrsti, propisao i izlaz iz tog stanja putem razvoda i raskida bračnog ugovora.

Međutim, ono što je činjenica i jedan vid društvene bolesti savremenog društva jeste da je taj ,podebljani, čvrsti bračni ugovor“ u savremeno doba postao tako rušljiv i toliko lahko raskidiv sa samo jednom riječju $\mathrm{u}$ afektu i bez svjedoka, da je to kod nas uzelo alarmantne i zabrinjavajuće razmjere. Ako tome dodamo loše uslove za život i da se mladi teško odlučuju na brak, onda je situacija zabrinjavajuća, a bijela kuga kuca sve jače i na naša vrata.

Naslovi u medijima često odražavaju ovo teško, alarmantno i zabrinjavajuće, statističko stanje i realnost gdje se došlo do situacije da je razvod sve češći "trend" u našem društvu na što upućuju poražavajući statistički podaci agencija za statistiku iz kojih se vidi da je više umrlih nego rođenih, da je manje brakova, a više razvoda. Crna bračna statistika pokazuje gotovo epidemiju razvoda tako da je posljednjih 10 godina u BiH "puklo" 20.000 brakova, da je samo u prošloj godini u našoj zemlji razvedeno 2.385 brakova, od čega najviše u Banjaluci gdje trenutno živi oko 7.240 razvedenih.

Kako statistike i praksa kažu, razvodi u $\mathrm{BiH}$ nikada nisu bili učestaliji. U 2019. godini u Tuzli, zabilježeno je čak 300 brakorazvodnih parnica. Osim što se razvode mladi, sve više se rastaju i oni stariji bračni parovi, nakon nekoliko decenija bračne zajednice.

\section{Pravni status svjedočenja kod razvoda i rastave u stavovima fikhske uleme}

Islamski pravnici su se razišli po pitanju svjedoka za razvod braka. Izrazita većina islamskih učenjaka smatra da se razvod može dati bez svjedočenja, jer je to diskreciono pravo muža kojim raspolaže autonomno, po svojoj volji, tako da mu svjedočenje nije potrebno.

Njihov argument je da nema dokaza iz sunneta Poslanika, s.a.v.s., što ukazuje na legitimnost svjedočenja za razvod, a isto tako muslimani su se, i u prošlosti pa do današnjeg vremena, rastajali bez svjedočenja razvodu braka što upućuje da je kur'anska pravna norma o svjedočenju samo ranga mustehaba, savjetodavna preporuka (kao i u ajetu o trgovanju) bez pravne snage obaveze (vadžib) propisa koji se derivira iz ajeta: 


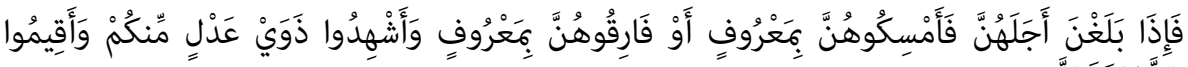

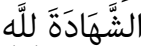

I dok traje vrijeme određeno za čekanje, vi ih ili na lijep način zadržite ili se velikodušno od njih konačno rastavite $i$ kao svjedoke dvojicu vaših pravednih ljudi uzmite, i svjedočenje Allaha radi obavite! (Kur'an, 65: 2)

Dakle, njihov stav je da ko upotrijebi svjedoke kod rastave, lijepo je, a nema nikakve sankcije ili ukora za onoga ko to ne učini. Za ovakav stav neki su, čak, naveli i konsenzus islamskih učenjaka ${ }^{3}$.

Ibni Kudame kaže: - Ako žena ustvrdi da je razvedena, a suprug to zaniječe, uzima se po njegovom svjedočenju, jer je osnova da brak postoji i da nije bilo razvoda, osim u slučaju da ona dokaže svoju tvrdnju s dva valjana svjedoka.

U slučaju da suprug tvrdi da se razvod dogodio, onda nisu potrebni svjedoci po ispravnom mišljenju izrazite većine uleme, pa čak se spominje i konsenzus u tome. ${ }^{4}$

Šejhul-islam Ibn Tejmije kaže:

-Kazao je Uzvišeni:

$$
\text { وَأَشْهِدُوا ذَوَيْ عَدْلٍ مِنْكُمْ وَأَقِيمُوا الشَّهَادَةَ للَّهِه. }
$$

i kao svjedoke dvojicu vaših pravednih ljudi uzmite, i svjedočenje Allaha radi obavite!; naređujući svjedočenje kod vraćanja žene u bračnu zajednicu. Naredba svjedočenja je konsenzus islamskog ummeta kroz dva pravna propisa: obaveze (vadžib) ili lijepog čina (mustehab).

Neki su pomislili da je razvod svjedočenjem i da razvod bez svjedočenja nije validan. Ovo je suprotno konsenzusu, Kur'anu i sunnetu. Takvo mišljenje nije zastupao niko od poznate uleme.

Prvo je dozvoljen razvod i nije naređeno svjedočenje za njega nego se naredba odnosi na kontekst iz ajeta: I dok traje vrijeme određeno za čekanje, vi ih ili na lijep način zadržite ili se velikodušno od njih

\footnotetext{
${ }^{3}$ www.iumsonline.org > ContentDetails

أيها العلماء أفتوا لا طلاق الا بشهود - الأتحاد العالمي لعلماء المسلمين

${ }^{4}$ Ibn Kudama, el-Mugni, 8/439.
} 
konačno rastavite; u kojem se hoće opoziva rastava, odnosno, rastava ako istekne iddet, a to stanje nije razvod, ni povrat žene, niti brak. Svjedočenje je za ovo po konsenzusu, tako da se, onda, odnosi na povrat žene (nakon opozivog rastavljanja) u bračnu zajednicu. Mudrost toga je u tome što suprug može da se rastavi pa da vrati ženu, krijući to, a poslije je rastavi zabranjenim razvodom za koji niko drugi ne zna, tako da žena bude sa njim u zabranjenom braku. Zbog toga je naredba svjedočenja kod povrata kako bi se ta opoziva rastava računala kao jedan razvod (talka) u slučaju da je muž doista vrati u bračnu zajednicu nakon toga. Tako je Allahov Poslanik, s.a.v.s., tražio svjedočenje i za nađenu izgubljenu stvar kako je nalazač ne bi prisvojio. Međutim, kod razvoda koji se finalno završi, a muž se ne vraća ženi, žena nije više s njim, prema tome, zna se da više nije njegova žena što je nasuprot opozive rastave kada je žena zajedno s mužem, a drugi još ne znaju da li su rastavljeni ili nisu. ${ }^{5}$

Stav da je svjedočenje obaveza za rastavu braka zastupaju ashabi: Alija b. Ebi Talib, Imran b. el-Husajn, Abdullah b. Abbas, r.a., tabiini: Muhammed el-Bakir, Dža'fer es-Sadik, A'ta, Ibn Džurejdž, es-Sedijj, Ibn Sirin, Tavus, Ebu Kalaba. ${ }^{6}$ Od pravnih eksperata, imam Šafija u svom starom mezhebu/mišljenju, imam Ahmed b. Hanbel u jednoj verziji predaje, Jahja b. Bukejr od malikija i Ibn Hazm od zahirija. Od savremene uleme to je stav Muhammeda Džemaluddina el-Kasimija, et-Tahira b. A'šura, kadije Ahmeda Šakira, ${ }^{7}$ Muhammeda Ebu Zehre, Alija el-Hafifa, Sejjida Sabika, ${ }^{8}$ Muhammeda el-Gazalija, Muhammeda Ahmeda es-Senhurija, Muhammeda Nasira el-Albanija, AbdurRahmana es-Sabunija i nekih drugih kao i velik broj savremene uleme sa El-Azhera. ${ }^{9}$

Njihovi argumenti su:

\footnotetext{
${ }^{5}$ Ibn Tejmijje, Fetava, 33/34.

6 Muhammed Džemaluddin el-Kasimi, El-isti'nasu litashih enkihatin-nas, (daru U'man, 1986/1406.) str.: 51.

${ }^{7}$ Ahmed Šakir, Nizamut-talak fil-islam, (PDF, 28. juni, 2017), str. 80.

${ }^{8}$ Sejjid Sabik, Fikhus-sunne, 2/260

${ }^{9}$ www.iumsonline.org > ContentDetails

أيها العلماء أفتوا لا طلاق الا بشهود - الأتحاد العالمي لعلماء المسلمين
} 
1. kur'anska norma (očigledno, jezičko značenje), 2. ajet iz sure etTalak:

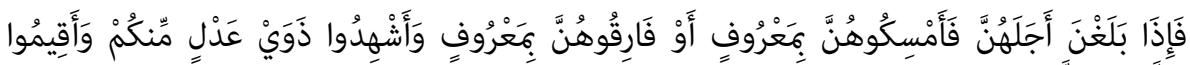
الَََّّهَادَةَ للَّهَ

I dok traje vrijeme određeno za čekanje, vi ih ili na lijep način zadržite ili se velikodušno od njih konačno rastavite i kao svjedoke dvojicu vaših pravednih ljudi uzmite, i svjedočenje Allaha radi obavite!

Ovo očigledno, jezičko značenje imperativa u šerijatskom običaju podrazumijeva obavezu, a to tumačiti i svesti samo na propis mustehaba, lijepog ili potpuno ukinuti pravno dejstvo norme, odstupanje je od šerijatskog običaja bez dokaza, uz činjenicu da se u ajetu ne pravi razlika između razvoda i svjedočenja za opozivi razvod.

2. Ebu Davud i Ibn Madže su zabilježili od 'Imran b. Husajna da je upitan o čovjeku koji je razveo ženu, a zatim vratio, ne tražeći svjedoke kod razvoda niti ponovnog vraćanja žene u bračnu zajednicu, pa je kazao tim slučajem:

$$
\text { طلَّقت لغير سنَّة، ورجعتَ لغيْرِ سنَّة، أشهِهْ على طلاقِها، وعلى رجْعَتِها، ولا تعُنْ }
$$

- Razveo si se protivno sunnetu i vratio ženu protivno sunnetu. Traži svjedoke kod razvoda, kod vraćanja žene u brak i ne vraćaj se (ranijoj praksi). ${ }^{10}$

Poznato je kod uleme metodologije islamske jurisprudencije da se izrijek ashaba računa sunnetom i tretira na stepenu vijesti vezane za Allahovog Poslanika, s.a.v.s., tako da je ovo tradicionalni argument.

3. Ibn Kesir spominje u svome tefsiru prenoseći od A'taa koji je kazao o riječima Uzvišenog: (...) i kao svjedoke dvojicu vaših pravednih ljudi uzmite, i svjedočenje Allaha radi obavite!, da nije dozvoljeno sklopiti brak, razvesti se ili se ponovo vratiti u bračnu zajednicu, osim sa svjedočenjem dva valjana svjedoka kao što je naredio Uzvišeni, izuzev ako postoji opravdanje za to. ${ }^{11}$

4. Ibn Hazm kaže: - Uzvišeni Allah je objedinio tri stvari: vraćanje žene u brak, razvod i svjedočenje tako da nije dozvoljeno rastaviti to jedno

\footnotetext{
${ }^{10}$ Tefsir Ibn Kesir, sura: et-Talak, ajet: 2. Albani ovu predaju smatra vjerodostojnom.

${ }^{11}$ Tefsir Ibn Kesir, sura: et-Talak, ajet: 2.
} 
od drugog. Onaj ko se razvede bez svjedočenja dva valjana svjedoka ili vrati ženu bez svjedočenja dva valjana svjedoka prekršio je Božiju normu, a onaj ko uradi nešto bez valjane norme ne prihvata mu se. ${ }^{12}$

Sejjid Sabik navodi: - Kada znamo da je obaveza svjedočenja kod razvoda stav poznatih ashaba i tabiina onda je jasno da tvrdnja konsenzusa u nekim fikhskim djelima kako je to mustehab, može da se odnosi samo na mezhebski konsenzus, ali ne i na terminološki kako se definira u metodologiji islamske jurisprudencije jer ne obuhvata slaganje velikog broja učenih ashaba, tabiina i savremene uleme. ${ }^{13}$

Izrazita većina uleme smatra naredbu svjedočenja u ajetu da je pravne snage mustehaba, iako je usulofikhska osnova da naredba ima pravnu snagu obaveze (vadžib) osim u slučaju postojanja okolnosti, konteksta ili indicije koja je obesnaži i spusti na stepen preporučenosti ili menduba.

Ibn Kudama obrazlaže:

Što se tiče svjedočenja postoje dva stava:

- obaveza i to je jedan od stavova Šafije pošto Uzvišeni kaže:

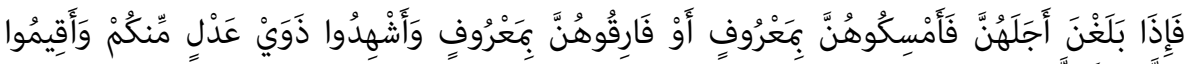
الشََّّهَادَة للَّنَ

I dok traje vrijeme određeno za čekanje, vi ih ili na lijep način zadržite ili se velikodušno od njih konačno rastavite i kao svjedoke dvojicu vaših pravednih ljudi uzmite, $i$ svjedočenje Allaha radi obavite!, a ovo je jasno, očigledno značenje koje podrazumijeva obavezu (vudžub) jer se ovdje radi o dozvoli bračnog odnosa tako da zbog toga svjedočenje postaje obaveza kao kod vjenčanja, za razliku od trgovine.

- ili nije obavezno; što je odabir Ebu Bekra, (jedno mišljenje) Malika i stav Ebu Hanife. Razlog je u tome što se tu ne traži prihvatanje (kabul) tako da nije potrebno ni svjedočenje kao kod drugih bračnih prava i iz razloga što ondje gdje ne postoji skrbnik (velij) ne uvjetuje se svjedočenje kao što je slučaj s trgovanjem. Prema tome, norma se

\footnotetext{
${ }^{12}$ www.fatihsyuhud.org > ... > Fiqh

الفصل الثاني أركان الطلاق - الكتب الإسلامية

13 Sejjid Sabik, Fikhus-sunne, 2/260. Vidi: Muhammed Džemaluddin el-Kasimi, Elisti'nasu litashih enkihatin-nas, (daru U'man, 1986/1406.) str.: 51.
} 
tumači pravnom snagom propisa mustehaba. Ne postoji razilaženje kod uleme da je svjedočenje na stepenu sunneta. ${ }^{14}$

Kurtubi u svom tefsiru kod spomenutog 2. ajeta iz sure Et-Talak obrazlaže komentar:

Riječi: - kao svjedoke dvojicu vaših pravednih ljudi uzmite - naredba je svjedočenja za razvod. Rečeno je, također: Za povrat žene u bračnu zajednicu. Međutim, očito jezičko značenje odnosi se na vraćanje žene u bračnu zajednicu, a ne za razvod. Međutim, ako bi se vraćanje izvršilo bez svjedočenja, onda imamo dva pravna stava o valjanosti vraćanja žene u bračnu zajednicu.

Rečeno je isto tako da riječi: uzmite svjedoke, znače za povrat žene $i$ za rastavljanje, zajedno.

Svjedočenje u ovoj prilici kod Ebu Hanife je mendub ili samo lijepo isto kao svjedočenja za trgovanje.

Šafija ga smatra obaveznim (vadžib) kod povrata žene, lijepim (mendub) kod rastave.

Korist od svjedočenja očituje se u tome da ne dolazi do nesporazuma $i$ svađa kod supružnika, da ne bude sumnje kod tvrdnji rastave ili povrata $i$ da kod smrti jednog od supružnika ne dođe do nesporazuma $u$ nasljeđivanju.

Ahmed b. Hanbel smatra da je svjedočenje obavezno kod povrata žene kao i imam Šafija zbog očigledne jezičke naredbe u ajetu.

Imami Malik, Ebu Hanife i Amed kao i Šafija u svom drugom stavu smatraju: - Povrat žene nije uslovljen prihvatanjem (kabul), prema tome nema potrebe za svjedočenjem kao za druga ostvarena prava ${ }^{15}(\ldots)$

Nevevi navodi: Svjedočenje za povrat žene u bračnu zajednicu nije uvjet niti obaveza po najočitijem stavu. ${ }^{16}$

Prema tome, kad svjedočenje kod povrata žene u bračnu zajednicu nije obaveza, onda nije ni kod razvoda. Čak da se hipotetički pretpostavi

\footnotetext{
${ }^{14}$ Ibn Kudama, El-Mugni, 7/522-533.

${ }^{15}$ Tefsir Ibn Kesir, sura: et-Talak, ajet: 2., (18/158.)

${ }^{16}$ En-Nevevi, Revdatut-talibin, 2/216.
} 
obaveza svjedočenja za razvod braka to ne uvjetuje valjanost razvoda osim sa svjedočenjem.

Imam Šafija kaže: Uzvišeni kaže:

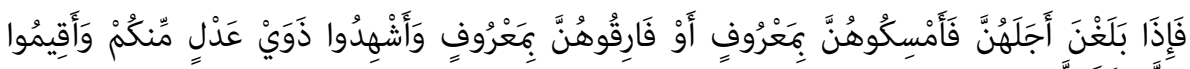
الشََّّهَاذَةَ للَّهِ

I dok traje vrijeme određeno za čekanje, vi ih ili na lijep način zadržite ili se velikodušno od njih konačno rastavite i kao svjedoke dvojicu vaših pravednih ljudi uzmite, i svjedočenje Allaha radi obavite! - Ovo je Božija naredba svjedočenja za razvod i povrat žene s određivanjem najmanjeg broja od dvaju svjedoka (...) Nisam susreo niti zapamtio nekog od uleme da je smatrao kako je razvod bez dokaza haram, prema tome, a Allah dragi najbolje zna, ovdje dokaz upućuje na izbor, a ne na obavezu (fard) čije izostavljanje bi bilo grijeh ${ }^{17}$ (...)

'Amr Selim u svojoj knjizi preferira stav da je svjedočenje kod razvoda i povrata žene mustehab pobijajući stav njegove obaveznosti:

- Mišljenje da su razvod i povrat žene bez svjedočenja neispravni nije ispravno i bez argumenta je. Čak kad bi hipotetički pretpostavili da je to obaveza proizišla iz ajeta, pa postupili suprotno, to ne bi poništilo pravno dejstvo razvoda niti povratka žene u bračnu vezu jer nas je Uzvišeni obavezao da se rastava žena čeka s iddetom kada je čista i muž ne opći s njom. A kada je Ibn Omer prekršio tu naredbu razvevši svoju ženu dok je bila u menstrualnom ciklusu, to je Poslanik, s.a.v.s., odobrio, iako je to bio prekršaj naredbe iz ajeta o razvodu, što nije bilo zaprekom da se računa jednim razvodom (talka), isto tako je i situacija sa svjedočenjem ${ }^{18}$.

Ovaj stav je ispravan jer čak i pod pretpostavkom da je svjedočenje u ovom slučaju obaveza, ipak, to nije uvjet bez čijeg se ispunjenja ne može razvesti.

17 Šafija, el-Umm, babuš-šehadeti fit-talak, str.: 89.

18 Amr Abdul-Mun'im Selim, el-Džami'u fi ahkamit-talak ve fikhihi ve edilletihi, (mektebetud-dija', Tanta), str.: 161. 


\section{Savjetodavna decizija, fetva i preporuka za IZ-u BiH}

- Rastava i razvod braka u savremeno doba postao je fenomen i svakodnevna društvena pojava iz razloga nepoznavanja vjere i imanske slabosti, kao i zbog brojnih ekonomskih, sigurnosnih, psiholoških i drugih pritisaka, koji su doveli do stalne napetosti, nerješavanja bračnih sporova i svađa, te brzopletosti da se zbog bizarnih, trivijalnih razloga, često u srdžbi i afektu, daje razvod, što rezultira raspadom porodice i dovodi do kidanja porodičnih veza, gubitka djece i opasnih, negativnih, društvenih posljedica koje iz svega toga proizlaze u muslimanskom društvu.

- Fenomen i savremeni, pojačani trend razvoda i rastave u društvu uključuje odgovornost učenjaka i pravnih eksperata da pored njihove primarne uloge u odgoju, obrazovanju i misionarenju ulože napor u pronalaženju odgovarajućih mjera i savremenih rješenja za organizovane islamske zajednice, u zemlji i dijaspori, kao odgovor ovom društvenom problemu i doprinos u pokušaju borbe i iskorjenjivanja savremenog trenda rasta razvođenja ili makar smanjenje ove, društveno ružne i negativne pojave.

- Stoga se nameće jedno od mogućih rješenja problema kroz interakciju u kojoj ulema treba da obrazloži i opravda jedan vid fetve, savjetodavne decizije, a koju će Islamska zajednica sprovesti i implementirati u džemate, a posebno džemate dijaspore. Fetva bi trebala glasiti: da se razvod muslimana, članova Islamske zajednice, kao $i$ vjenčanje obavlja $i$ zvanično registruju pred svjedocima i sluz̆benikom Islamske zajednice.

Hoće li se to temeljiti na fikhskom propisu obaveze (vadžib) ili izbora lijepog, dobrovoljnog propisa (mustehab, nedb) što je stav hanefijskog mezheba, birajući i preferirajući jedno od ekspliciranih fikhskih rješenja, u ovom radu nije krucijalno jer se članstvo u Islamskoj zajednici u osnovi oslanja na autonomiju volje džematlija i principu dobrovoljnosti.

Stav da je za razvod potrebno svjedočenje koje je uvjet njegove valjanosti može da ima logično, pravno uporište, ali da bude uvjet valjanosti razvoda je, ipak, veoma diskutabilno. Međutim, opće neznanje, nepoznavanje vjere, posebno propisa koji se tiču bračnog prava, zatim savremeno neprijateljstvo usmjereno prema porodici kao osnovnoj ćeliji društva, opći javni interes te pokušaj preventivnog 
djelovanja u sprečavanju razvoda vodi nas ka tome da i za razvod treba biti uslov svjedočenje pošto nije logično da islamsko šerijatsko pravo toliko pooštreno uslovljava uvjete za sklapanje braka, naziva ga (misakan galizan - podebljani, čvrsti ugovor), zatim postavlja uvjete za sklapanje, ispravnost, valjanost, legitimitet i zakonitost bračnog ugovora, a onda to sve ,podebljano, čvrsto, jako“ poruši samo jednom riječju supruga u srdžbi, afektu i bez traženja svjedoka, čime se desi razvod i nastupe njegove pravne posljedice!

Važno je da IZ u svome administriranju to zatraži oficijelnom fetvom i to je najbitnije. A očekivane koristi od fetve mogu biti ogromne:

1. smanjiti procenat razvoda;

2. fetva je u skladu same prirode šerijata koji nastoji sačuvati prava pooštrenim mjerama kao što je svjedočenje koje je uvjet za sklapanje braka, a za razvod je, možda, i preče;

3. traganje za svjedocima i njihov pronalazak daje suprugu novu mogućnost da se preispita i možda odustane od razvoda;

4. za svjedočenje se uzimaju prijatelji i rodbina koji će nanovo pokušati da se prevaziđe problem razvoda i riješi pomirenjem, što je nova šansa da brak opstane;

5. isto tako, svjedoci su korisni za eventualne buduće parnice, razmirice i pridonose pravednijem rješenju ovog problema, $i$ što je najbitnije

6. kada se taj čin obavlja pred vjerskim autoritetom, službenikom islamske zajednice, glavnim imamom, teologom itd. i uz prisustvo ozbiljnih svjedoka, sve to je dodatno podebljavanje riješenosti da se taj ,podebljani, čvrsti ugovor“" (misakan galizan), završava i raskine isto tako podebljanom čvrstom riješenošću za razvod, ali nakon poduzetih svih mogućih mjera i sredstava da do toga ne dođe. Tek kada se vidi da u braku više ne postoji mogućnost zajedničkog života, onda se ozvaniči i registruje razvod. Prema tome, ako je uloga vjerskog autoriteta uz svjedoke i registraciju potrebna za vjenčavanje i stupanje u brak, onda isto tako je i na kraju bračne veze u razvodu, da svojim savjetima i uputama pomogne rješavajući sve eventualne vjerske nedoumice parova koji se razilaze.

Vallahu e'alemu! 


\section{Literatura:}

El-Kur'anu-l-kerim, Mushafu-l-Medinetin-Nebevijjeh, Kur'an Časni, medinska verzija Mushafa; Mudžemme'u-l-melik Fehd, (1405. h.),

Korkut, Besim, Kur'an s prevodom, S. Arabija, Medina: Štamparija kralja Fehda, (1412. h.),

The Zekr Project El-Kur'anul-kerim.

\section{Citirana literatura:}

Ahmed Šakir, Nizamut-talak fil-islam, (PDF, 28. juni, 2017),

Amr Abdul-Mun'im Selim, El-Džami'u fi ahkamit-talak ve fikhihi ve edilletihi, (mektebetud-dija', Tanta),

Ibn Kesir, Tefsir Ibn-Kesir, skraćeno izdanje, Izabrao najispravnije verzije Muhammed Nesib er-Rifa'i, (Visoki saudijski komitet, Sarajevo, 2000),

Ibn Kudame, Abdul-Muhsin Et-Turki i dr. Abdul-Fettah El-Hilv (1992), ElMugni, Kairo: Hidžr,

Ibn Tejmije, Medžmu'u fetava (Zbirka decizija), (Izdanje kralja Fehda b. 'Abdulaziza, 1398),

Jahja b. Šeref en-Nevevi, Revdatut-talibin, (Daru a'lemil-kutub, 2003/1423.h.),

Muhammed Emin, poznat kao Ibnu 'Abidin, Hašijetu reddi-l-muhtar, poznata kao Hašijjetu Ibni 'Abidin (Glosa Ibni 'Abidina), (Daru-l-fikr, 1979),

Muhammed b. Idris eš-Šafi'i, El-Umm, kompendijum Muzenija, (Daru-1ma'rife, Bejrut, Libanon),

Muhammed Nesib er-Rifa'i, Tejsiru-l- 'Alijji-l-kadir lihtisari tefsir Ibn Kesir, (Bejrut, 1978),

Muhammed Džemaluddin el-Kasimi, El-isti'nasu litashih enkihatin-nas, (daru U'man, 1986/1406),

Sejjid Sabik, Fikhus-sunne, (Daru-1-fikr, Bejrut, 1977),

Vehbe ez-Zuhajli, El-Fikhul-islamijju ve edilletuh, (Darul-fikr, Damask, 1984),

\section{Internet:}

www.fatihsyuhud.org > ... > Fiqh 
; posjećeno, 14. august, 2020.الفصل الثاني أركان الطلاق - الكتب الإسلامية

www.iumsonline.org > ContentDetails

; posjećeno, 14. august, 2020. أيها العلماء أفتوا لا طلاق الا بشهود - الأتحاد العالمي لعلماء المسلمين. 
Muharem Štulanović, PhD

University of Bihac

Islamic Pedagogical Faculty

E-mail:ebuseba@botmail.com

\section{THE NEED FOR A FATWA FROM THE B\&H ISLAMIC COMMUNITY ON TESTIFYING IN DIVORCE AND THE WIFE RETURNING}

\section{ABSTRACT}

It is well known that marital, family law and divorce have their own legal sharia regulations which have been processed by lawyers from a legal, fiqh aspect. Divorce becomes enforceable with pronouncing and terms of divorce after the post-marriage waiting is over.

The ulema share the opinion that divorce is accepted in a situation when the spouse (legal addressee) says the terms / expressions of an irrevocable divorce, even if he did not intend to divorce, according to the hadith:

There are three things which, whether undertaken seriously or in jest, are treated as serious: marriage, divorce and taking back a wife (after a divorce which is not final).

The ulema of the Islamic ummah agree that the basis of divorce is the linguistic pronunciation of terms / expressions that mean divorce, which can be expressed in writing, as well as in sign language and isharet. In this sense, there are Qur'anic-Hadith texts and norms which speak of divorce.

Divorce is a linguistic, verbal procedure by a husband who gives a divorce by his autonomy of will. It is his discretion, not a contract in which two wills or a woman's permission should coincide.

At this time, when there is general viciousness and immorality, people should be obliged to register and record important but also less important contracts in order to prevent the taking, appropriation or lossing of rights that are not recorded and written down in order to stop altercation and intolerance due to property and other misunderstandings.

In this sense, witnessing and registration of marriage, as well as separation and divorce, have become a necessity in the Islamic Community of Bosnia and Herzegovina with the well-known fact that it is an usual practice in conventional law, as well as in some modern, Muslim countries. 
Key words: marriage, marital union, divorce, legal separation, witnessing in divorce and legal separation, postmarital waiting / iddet. 


\section{الأستاذ الدكتور محرم شتولانوفيتش \\ جامعة بيهاتش \\ كلية التربية الإسلامية \\ ebuseba@hotmail.com}

\section{الحاجة إلى فتوى من المشيخة الإسلامية في البوسنة والهرسك بشأن شهادة الطلاق وعودة المرأة لزوجها لئل النوسية}

\section{الخلاصة}

بسم الله، والحمد لله، والصلاة والسلام على رسول الله، وعلى آله وصحبه، أما بعد:

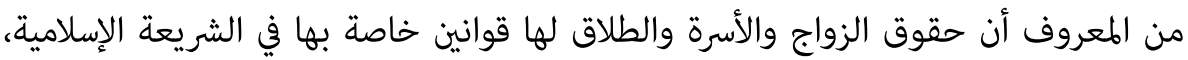

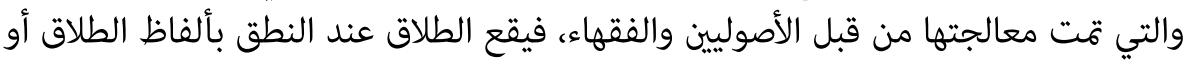
بالألفاظ التي تتضمن معنى الطلاق بعد انتهاء العدة. 19

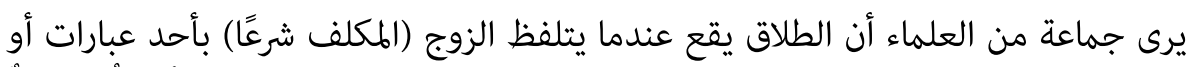

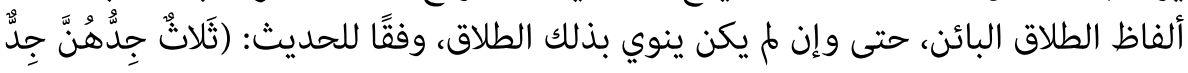

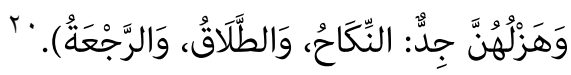

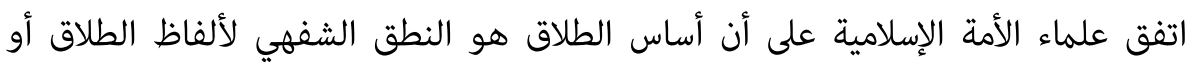

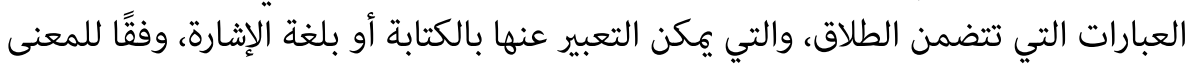

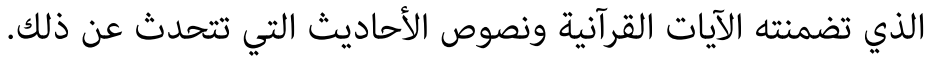

الطلاق هو فعل شفهي لفظي، يقوم به الزوج الراغب في الطلاق بإرادته الحرة، وهو حقه إنها الشرعي وليس عقدًا يوجب اتفاق الطرفين أو يتطلب إذبنًا من المرأة.

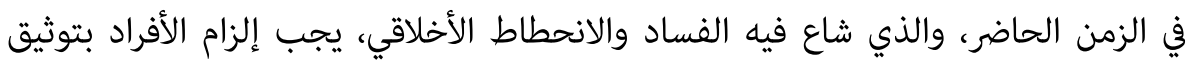

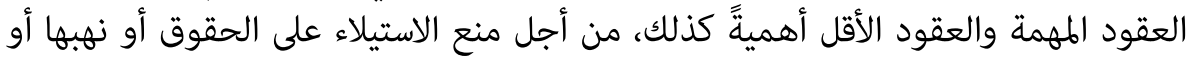

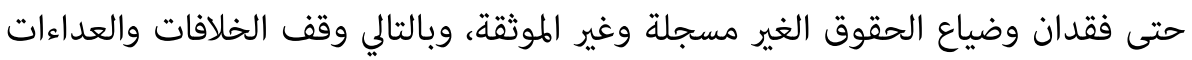

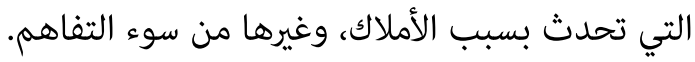

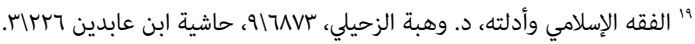

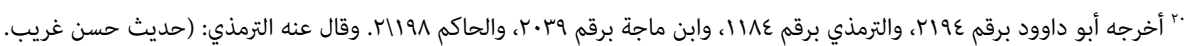

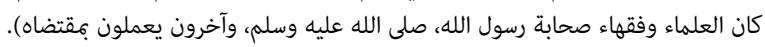




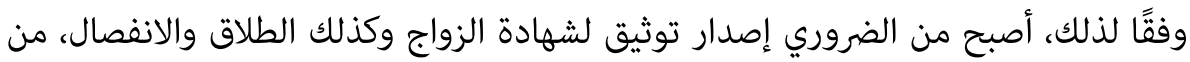

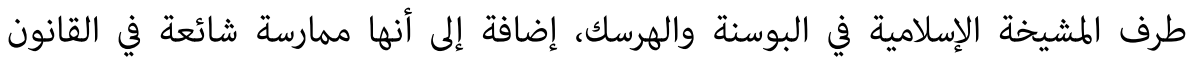
الوضعي وكذلك في بعض الدول الإسلامية المتطورة. الكلمات المفتاحية: زواج، زوجية، طلاق، انفصال، شهادة الطلاق، العدة. 